\title{
Carcinoma of the ovary
}

A symposium held at St Thomas's Hospital, London S.E.1, on 8 June 1972

Organizers

\author{
Dr M. G. Brush DR A. W. Harcus
}

Ovarian cancer: some new analytical approaches

K. Griffiths, W. J. Henderson, J. A. Chandler and C. A. F. Joslin

Experimental approaches to endometrial and ovarian cancer

M. G. BRUSH

The use of oestradiol uptake and binding-site studies in endometrial and ovarian carcinoma

R. W. TAYLOR, M. G. BRUSH and R. J. B. KING

Statistical aspects of a co-operative trial on the treatment of ovarian carcinoma

K. D. MACRAE

Ovarian cancer clinical survey

A. W. Harcus

\section{Ovarian cancer: some new analytical approaches}

K. GRIFFITHS

B.Sc., PH.D.

J. A. Chandler

B.SC. F.R.MICRO.SOC.

\author{
W. J. HENDERSON \\ F.R.MicRo.SOC.
}

C. A. F. JoSLIN
M.B., F.F.R., D.M.R.T.

Tenovus Institute for Cancer Research, Welsh National School of Medicine, Heath Park, Cardiff CF4 4XX

DESPITE the complex nature of the ovary, with its interrelated cell types and cyclical changes in secretory activity, experimental studies, both in vitro and in vivo have provided a considerable amount of information concerning the biosynthesis of steroid hormones by ovarian tissue. In particular, the investigation of Savard, Marsh \& Rice (1965) would suggest, as far as synthesis is concerned, that some degree of compartmentalization is involved, the follicle being primarily the source of oestrogens, the corpus luteum the site of production of progesterone and the ovarian stroma or interstitium responsible for androgen synthesis. Moreover, biochemical studies with tissue from 'functional' ovarian tumours which histologically could be recognized and identified according to the generally accepted form of tumour classification (Morris \& Scully, 1958) have indicated that the steroid biochemistry of these neoplasms was usually related quite closely to the associated endocrine disturbance of the patient (Griffiths et al., 1971). A number of such investigations have been described involving the oestrogen-producing granulosa theca-cell tumours, androgen-secreting arrhenoblastomas and hilus cell tumours and many others of this group referred to as the 'functional' or hormone-secreting neoplasms (Griffiths et al., 1971).

During the past two decades, however, there have been reports that clinical manifestations associated with excessive oestrogen secretion can accompany the presence not only of certain 'non-functional' tumours (Morris \& Scully, 1958; Novak \& Woodruff, 1958) such as the primary ovarian carcinomas, cystadenofibromas and serous cystadenomas, but also secondary ovarian tumours derived from such primary sources as cancers of the gastro-intestinal tract (Scott, Lumsden \& Levell, 1967; Conner et al., 1968). It has been suggested that in the case of the secondary tumour, there is a localized stromal reaction to the presence of metastatic tissue. This would result in the formation of the 'theca-lutein' cells from the stromal tissue surrounding the 
developing tumour, and these cells have been considered responsible for oestrogen secretion. The histochemical studies of Scully \& Cohen (1964) and the demonstrated steroid biosynthetic capacity (Savard et al., 1965) would indicate that the ovarian stroma is more complex than merely a supporting medium for the germinal tissue. Although there is no direct evidence that such cells actively synthesize oestrogen, experiments in vitro indicate the presence of enzymes capable of oestrogen synthesis in the tissue from such tumours (Plotz et al., 1967; Griffiths et al., 1971). The possibility exists that oestrogen production localized at the site of the early stromal reaction to the presence of the metastases may play some role in the development of the tumour.

Furthermore, it also appeared reasonable to suppose that material such as asbestos fibres, suggested as being associated with the aetiology of ovarian cancer (Graham \& Graham, 1967; Keel, 1960) could well form the focus of a similar type of stromal reaction and early malignant changes in the primary tumour. Work in our laboratories has resulted in the development of an extractionreplication technique for the investigation and identification of foreign particles within biological tissues (Henderson, 1969). Although this procedure was used for the in situ identification of crocidolite asbestos within mesotheliomas (Henderson, Harse \& Griffiths, 1969), its application to a study of various ovarian tumours clearly indicated the absence of asbestos fibres within the tissue (Henderson et al., 1971). However, of particular interest was the demonstration that there were particles of talc in the tumours studied. Talc, a magnesium silicate, was recognizable because of the 'decorative pattern' induced by evaporation of platinum in vacuo on the crystal surface (Fig. 1a and b).

The relationship between asbestos and carcinogenesis is well recognized (Wagner, Sleggs \& Marchand, 1960). As yet, there is no evidence to suggest that the particles of talc are concerned as a primary cause of carcinomatous change, but further investigations are obviously in order. Such investigations are currently being facilitated by the use in our laboratories of analytical electron microscopy. EMMA 4 (Chandler, 1971), the recently installed electron microscope micro-analyser (Fig. 2) allows for the identification of foreign particles in tissue while relating them to ultrastructural changes which may be occurring therein. The technique makes use of the fact that electrons, passing through an ultrathin specimen to form an electron image, also generate, from the irradiated specimen area, X-rays with energies characteristic of the elements of which the specimen is composed. An atom of silicon in a particle of magnesium silicate or talc, when struck by an incident electron,

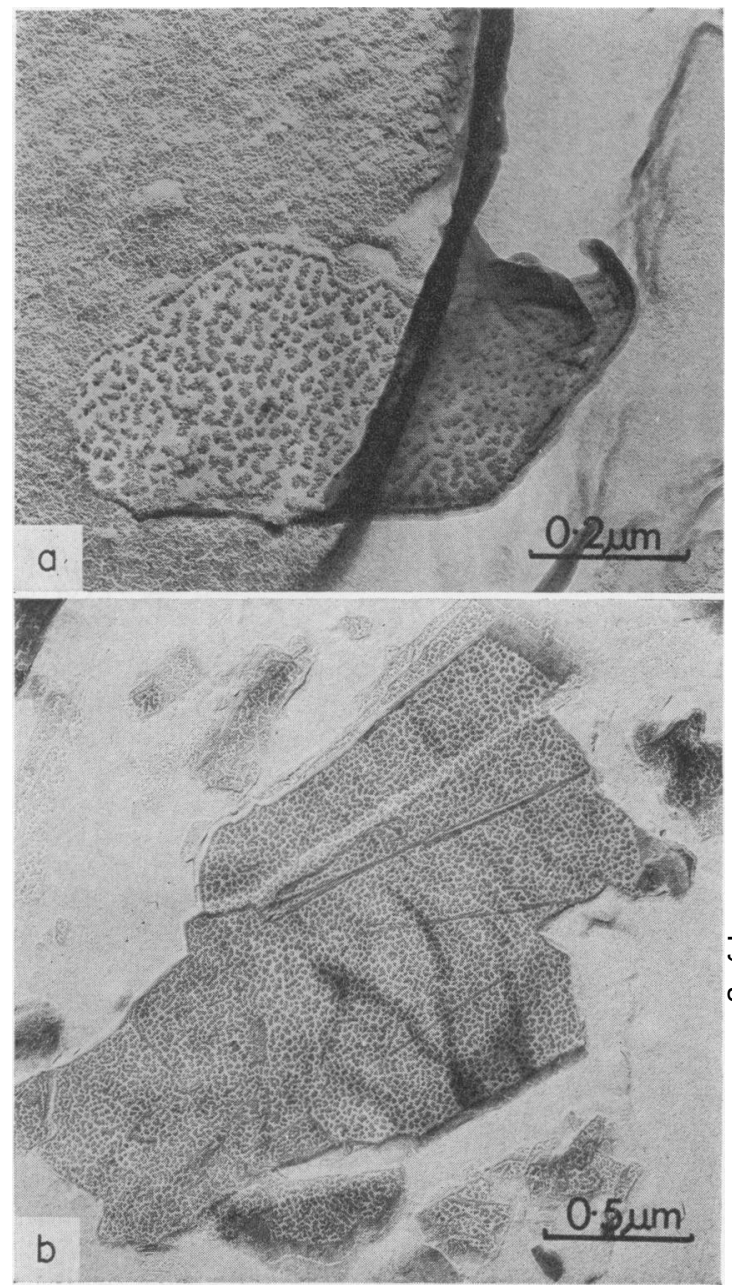

FIG. 1. (a) A minute particle of talc, displaying the characteristic decoration pattern, extracted from a pseudomucinous carcinoma of the ovary. $\times 133,000$. (b) Particles of talc from a cosmetic preparation demonstrating the decoration pattern. A number of lattice planes are also evident. $\times 50,000$.

will emit an X-ray photon having a well defined energy and different from that emitted by an atom of magnesium. These emitted X-rays are collected both with a solid state detector coupled to a multichannel analyser, and simultaneously with crystal spectrometers.

The region of the specimen chosen for analysis is selected by focusing the illuminating electron beam on to a small area which is visible as the transmission image projected onto the microscope screen. Use of a 'mini-lens' can focus the electron beam onto the foreign cystalline particle so that it becomes the 


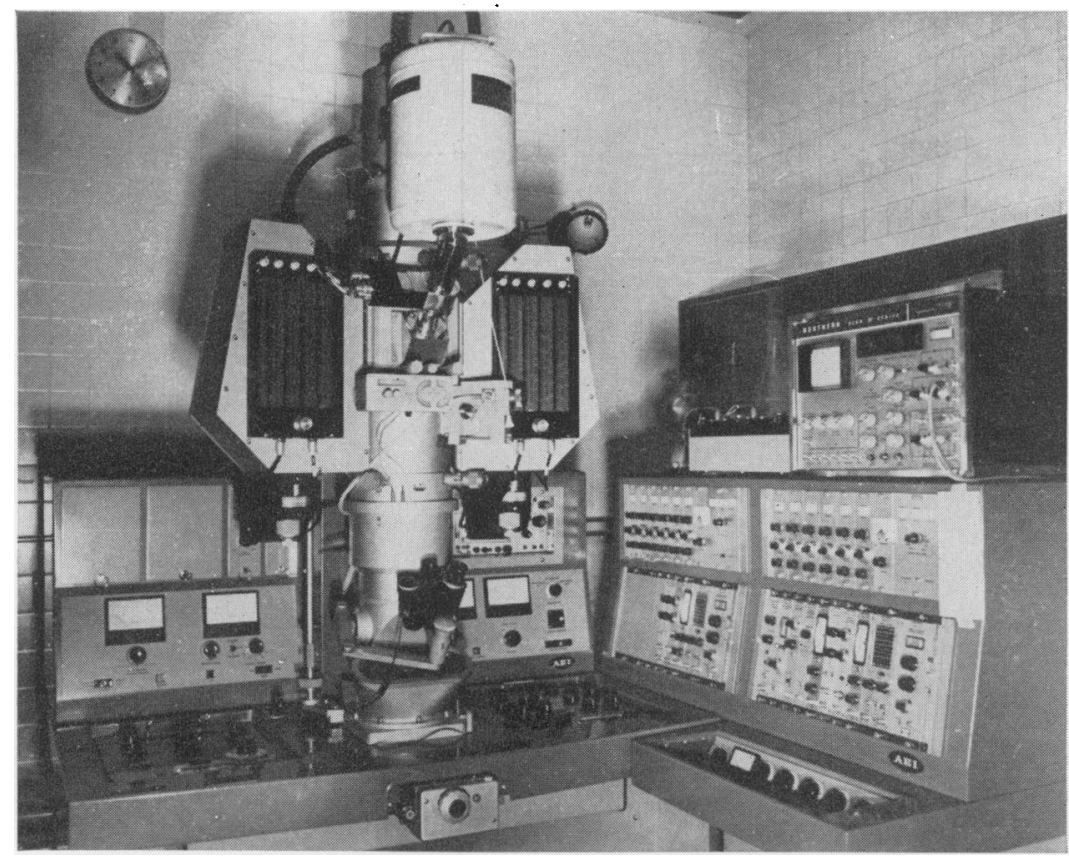

only part of the specimen emitting X-rays. Particle preparations are produced by use of the extractionreplication technique (Henderson, 1969) (Fig. 3) or in specimens of tissue in ultrathin form so that studies into the intracellular localization become possible. Our studies have shown that the well-

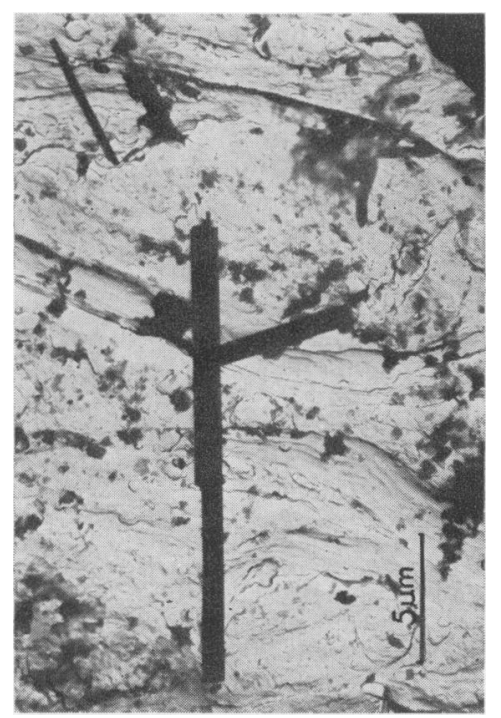

Fig. 3. Asbestos fibres adhering to an extraction-replica of mesothelioma tissue. $\times 6000$. known difficulties of investigating tissue inclusions by ultrathin sectioning, with the characteristic dislodgment of the particle under electron irradiation,

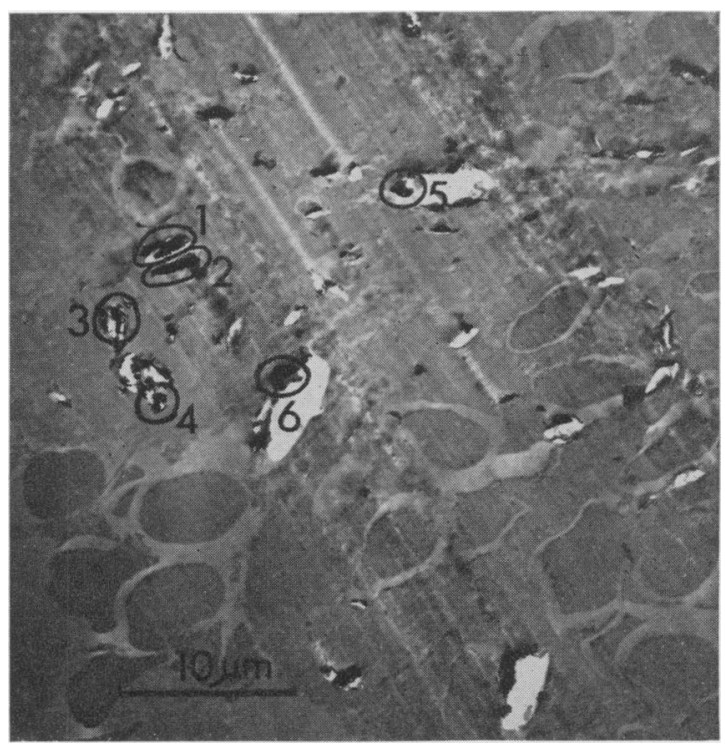

FIG. 4. Ultrathin section of ovarian tissue previously prepared for histological examination; the use of a double carbon sandwich technique allowed the particles outlined to be analysed. $\times 3000$. 


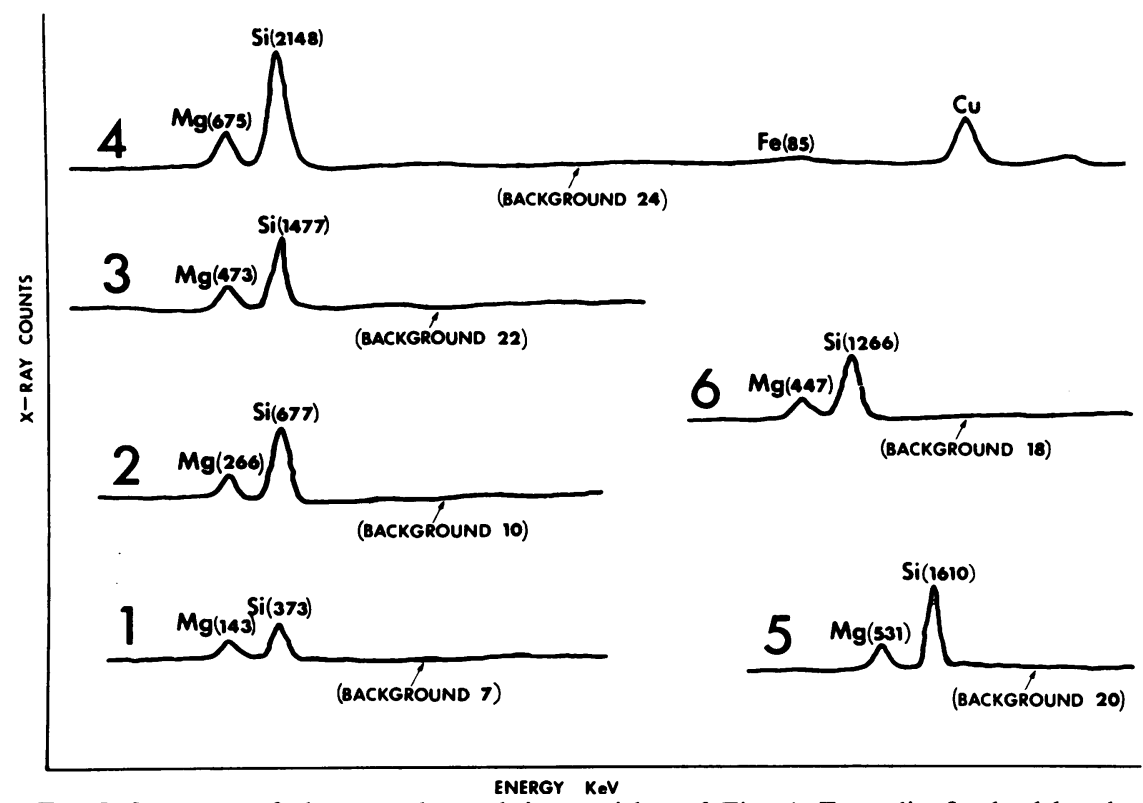

FIG. 5. Spectrum of elements detected in particles of Fig. 4. Formalin fixed-delayed Araldite embedding. Counting time $30 \mathrm{sec}$.

can be partially overcome by use of the double carbon sandwich procedure (Fig. 4).

The whole X-ray energy spectrum from all elements present in the particle is collected at the solid state detector, and displayed on the multichannel analyser as an accumulated spectrum intensity over a selected period of time. Such a spectrum is shown in Fig. 5. A typical analysis time to obtain the full elemental spectrum from a single particle with dimensions of the order of $1 \mu \mathrm{m}$ is $100 \mathrm{sec}$. This spectrum gives a qualitative assessment of the elemental nature of the particle. For accurate quantitative identification, the crystal spectrometers are used which collect and display X-rays from individual elements.

Such procedures provide the means by which foreign crystalline materials found in biological tissue can be readily analysed. The study of embedded talc particles in ovarian tissue from both human and also experimental animals can be made easier by the use of EMMA, and the development of ultrathin sectioning techniques should allow crystal identification in relation to possible changes in the morphology of the tissue surrounding the foreign inclusion.

\section{References}

Chandler, J.A. (1971) Analytical electron microscope. American Laboratory. April, 3, 50.

Conner, T.B., Ganis, F.M., Levin, H.S., Migeon, C.J. \& MARTIN, L.G. (1968) Gonadotrophin-dependent Krukenberg tumour causing virilization during pregnancy. Journal of Clinical Endocrinology and Metabolism, 28, 198.
Graham, J. \& Graham, R. (1967) Ovarian cancer and asbestos. Environmental Research, 1, 115.

Griffiths, K., FaHmY, D., Henderson, W.J., Turnbull, 응 A.C. \& Joslin, C.A.F. (1971) In: Control of Gonadal Steroid Secretion (Ed. by D. T. Baird \& J. A. Strong), p. 281. Edinburgh University Press. Edinburgh.

HENDERSON W.J. (1969) A simple replication technique for the study of biological tissues by electron microscopy. Journal of Microscopy, 89, 369.

Henderson W.J., Harse, J. \& Griffiths, K. (1969) A replication technique for the identification of asbestos fibres in mesotheliomas. European Journal of Cancer, 5,621.

Henderson, W.J., Joslin, C.A.F., Turnbull, A.C. \& GRIFFITHS, K. (1971) Talc and carcinoma of the ovary and cervix. Journal of Obstetrics and Gynaecology of the British Commonwealth, 78, 266.

KeEL, E.E. (1960) Asbestosis and abdominal neoplasms. Lancet, ii, 1211.

MoRris, J.M. \& Scully, R.E. (1958) Endocrine Pathology of the Ovary. The CU Mosby Co. Ltd., St Louis.

NovaK E. \& WoODRUFF, E.R. (1958) Gynecologic and Obstetric Pathology, 4th edn., p. 402. W. B. Saunders Co., Philadelphia/London.

Plotz, E., Wiener, M., Stein, A.A. \& Hahn, B.D. (1967) Enzymatic activity related to steroid synthesis in common ovarian cancer. American Journal of Obstetrics and Gyneco$\log y, 97,1050$.

SAVARD, K., MaRsh, J. \& RICE, B.F. (1965) Gonadotrophins and ovarian steroidogenesis. Recent Progress in Hormone Research, 21, 285.

ScotT, J.S., Lumsden, C.F. \& Levell, M.J. (1967) Ovarian activity in association with hormonally inactive neoplasia. American Journal of Obstetrics and Gynecology, 97, 161.

Scully, R.E. \& CoHEN, R.B. (1964) Oxidative-enzyme activity in normal and pathologic human ovaries. Obstetrics and Gynecology, 24, 667.

Wagner, J.C., Sleggs, C.A. \& Marchand, P. (1960) Diffuse pleural mesothelioma and absestos exposure in the North Western Cape Province. British Journal of Industrial Medicine, 17, 260. 